\title{
The E-CARE Project - Removing the Wires
}

\author{
Andy Marsh \\ VMW Solutions Ltd, \\ 9 Northlands Road, Whitenap, Romsey, \\ Hampshire SO51 5RU, UK \\ Andy.Marsh@VMWSolutions.com
}

\begin{abstract}
The European Commission IST project called E-CARE: Medical Expert System for Continuity of Care and Healthy Lifestyle presents innovative health services that will introduce new practices in health monitoring and decision support on health matters as well as healthy living. E-CARE will cater for a wide range of scenarios, from patients on short-term (1-2 months) recovery from treatment to patients with long-term illness, elderly people and people predisposed to diseases, which live a normal life but at the same time need constant attention on the state of their health. One aspect of E-Care that is the major issue for the introduction of $3 \mathrm{G}$ Medical services in general is the systematic removal of the connecting wires which link the patients vital data sensors to the medical server which is monitoring the patient. This paper presents the steps adopted within the E-Care project and therefore a blue-print for developing further $3 \mathrm{G}$ Medical services.
\end{abstract}

\section{Introduction}

The European Commission IST project called E-CARE: Medical Expert System for Continuity of Care and Healthy Lifestyle presents innovative health services that will introduce new practices in health monitoring and decision support on health matters as well as healthy living. E-CARE will cater for a wide range of scenarios, from patients on short-term (1-2 months) recovery from treatment to patients with longterm illness, elderly people and people predisposed to diseases, which live a normal life but at the same time need constant attention on the state of their health. E-CARE will empower medical doctors to constantly and remotely keep track of their patients' vital parameters (using medical devices with communication abilities), with minimum effort, assisted by an intelligent automated infrastructure. At the same time family and friends of the patients will too have access to the same information, filtered and presented in a comprehensible manner, including latest comments from the doctors. A sophisticated Collaboration Model will manage the whole service and will be aware of each patient's medical record, providing an information channel between the medical staff, the patients and their carers.

The application domains for E-Care have been identified as Elderly, Oncology and Paediatric Oncology. Collectively these domains have identified the follow key ambulatory parameters that are to be monitored: 
For the I

\begin{tabular}{|l|l|}
\hline Heart rate & Sensitive but non-specific sign of cardiac function. \\
\hline Activity & $\begin{array}{l}\text { Two, dual axes accelerometers, one over the abdomen and the } \\
\text { other on lateral aspect of upper thigh indicate activity through } \\
\text { measurement of accelerations during walking and running. }\end{array}$ \\
\hline Body temperature & Intermittent values of temperature. \\
\hline $\begin{array}{l}\text { \%Vital Capacity } \\
\text { expired in one sec } \\
\text { (\%VC 1 sec) }\end{array}$ & $\begin{array}{l}\text { \%VC 1 sec reflects severity of airways obstruction in chronic } \\
\text { obstructive pulmonary disease. }\end{array}$ \\
\hline Blood Glucouse & $\begin{array}{l}\text { Prevent or delay vascular (blood-vessel) or neurological } \\
\text { (nerve) complications }\end{array}$ \\
\hline EEG & $\begin{array}{l}\text { Needed to diagnose the presence and type of seizure disorders, } \\
\text { confusion, head injuries, brain tumors, infections, degenerative } \\
\text { diseases, and metabolic disturbances that affect the brain }\end{array}$ \\
\hline
\end{tabular}

For the Oncology:

\begin{tabular}{|l|l|}
\hline ECG waveform & $\begin{array}{l}\text { Needed to interpret cardiac arrhythmias; in some instances, } \\
\text { requires addition of jugular venous pulse to distinguish atrial } \\
\text { contraction to diagnose type of tachyarrhythmia and heart } \\
\text { blocks. }\end{array}$ \\
\hline Blood pressure & $\begin{array}{l}\text { Intermittent values of blood pressure by oscillometric } \\
\text { technique. }\end{array}$ \\
\hline $\begin{array}{l}\text { Medication } \\
\text { reminder }\end{array}$ & $\begin{array}{l}\text { Description with audio-visual beeps for time medication } \\
\text { reminder prompt. }\end{array}$ \\
\hline $\begin{array}{l}\text { Arterial oxygen } \\
\text { saturation }\end{array}$ & $\begin{array}{l}\text { Assesses amount of oxygen in arterial blood and is a } \\
\text { component of sleep study. }\end{array}$ \\
\hline
\end{tabular}

For the Paediatric Oncology:

\begin{tabular}{|l|l|}
\hline Body temperature & Intermittent values of temperature. \\
\hline Body weight & Intermittent values of body weight \\
\hline Pain & Description through Visual Analogue Scale. \\
\hline
\end{tabular}

One aspect of E-Care that is the major issue for the introduction of 3G Medical services in general is the systematic removal of the connecting wires which link the patients vital data sensors to the medical server which is monitoring the patient. The following steps illustrate the approach adopted within the E-Care project and therefore a blue-print for developing further 3G Medical services:

\section{Step 1: Removing the data logger's RS232 link}

The vital data sensors are connected to a data logger that is carried by the patient. The data logger is connected via an RS232 link to a client PC located in the patients home. This home PC is connected via a fixed line connection to the monitoring server that analyses the patient's vital data and generates an alarm, an updated report or an 
emergency call. The first step is to replace the data logger's RS232 link with an Radio Frequency (RF) link.

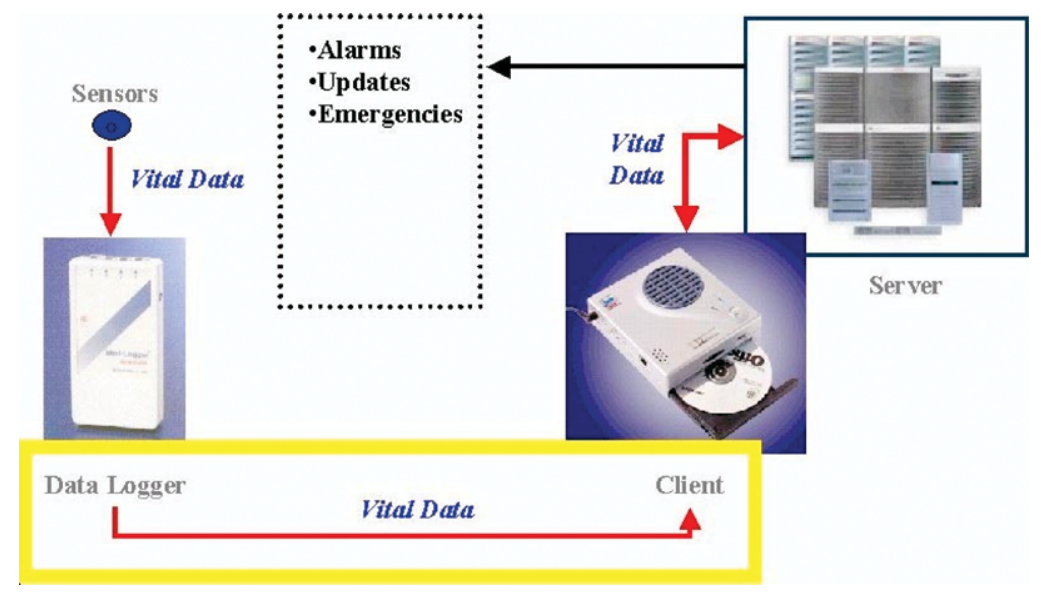

Fig.1. Step 1: Removing the data logger's RS232 link

\section{Step 2: Adding GSM mobility}

The RF link will allow the patient, who in this scenario is an elderly person, to move within the range of the RF transceivers $(200 \mathrm{~m})$ and still have the data from their sensors, which in this case includes movement, temperature and pulse, continuously monitored. This approach supports home care monitoring but confines the patient to always be within RF range if they want to be continuously monitored. To overcome this limitation GSM networking can be used.

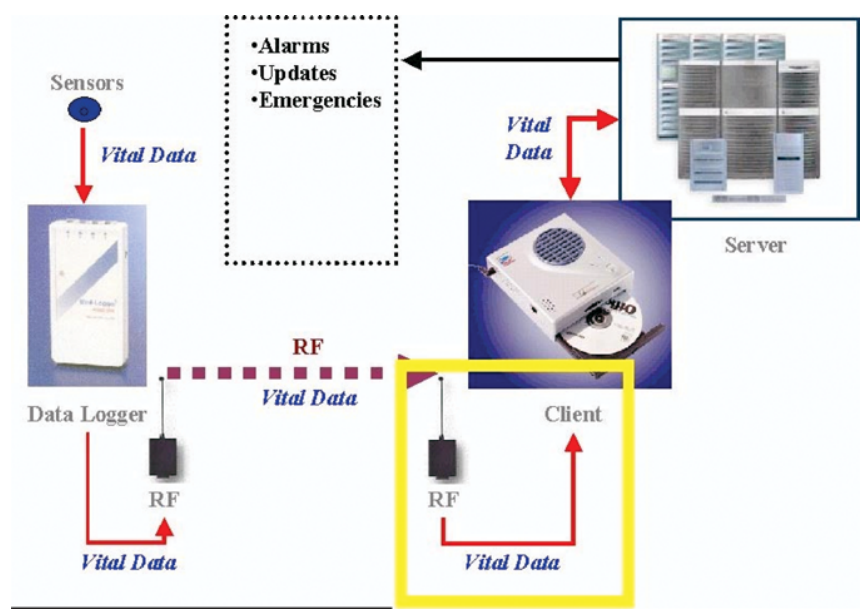

Fig.2. Step 2: Adding mobility 


\section{Step 3: Personalizing patient alarms}

By using GSM networks, the patient's sensors via the data logger and RF transceivers can be connected to a GSM modem (for example the patients mobile handset) that can periodically transmit using SMS the patient's vital data to a receiving GSM modem connected to a home PC. The home PC can then upload the vital data to the monitoring server. When this service is used for monitoring outpatients, for example oncology patients, the detection of an alarm may be dependent on customized historic data.

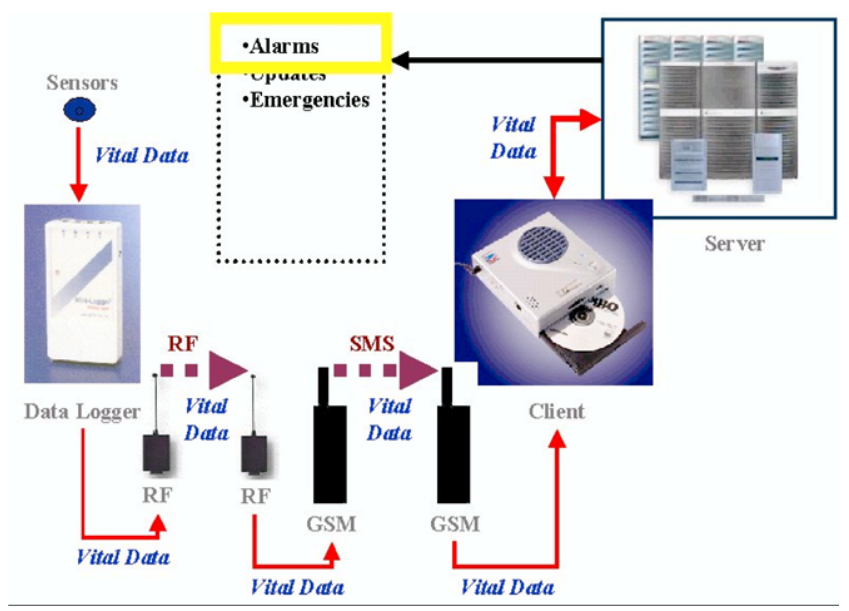

Fig.3. Step 3: Personalizing patient alarms

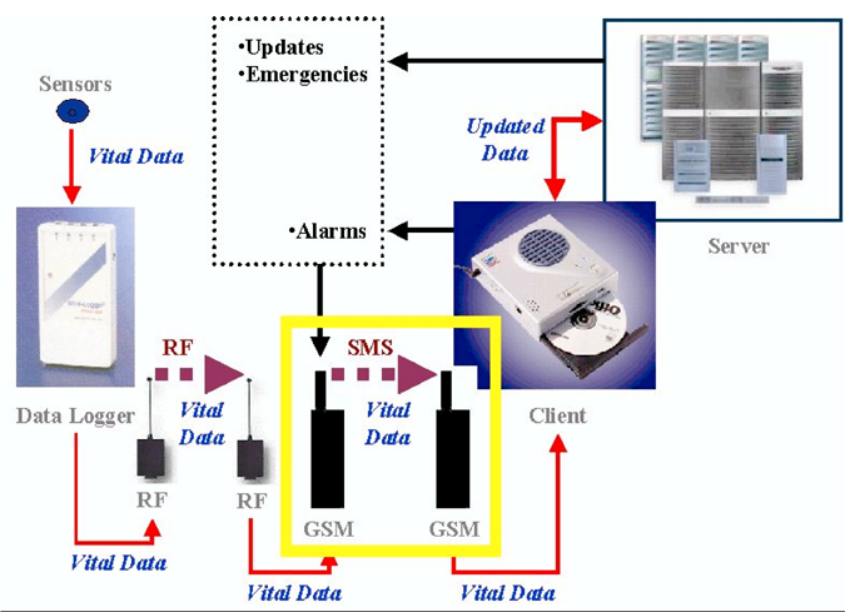

Fig. 4. Step4: Using 2.5G networking 


\section{Step 4: Using 2.5G networking}

By using the home PC to detect an alarm situation the patient could be warned, on their mobile handset, of an arising situation such as their pulse is to high or even a calendar type of event, such a drug reminder, without the monitoring server being involved. By using SMS communications to transmit the patients data the service is limited. A logical extension would be to use $2.5 \mathrm{G}$ networking namely GPRS for the transmission of the vital data.

\section{Step 5: Using Wireless sensors}

By using GPRS networks the patient has not only mobility but also the facilities for a larger amount of data communication from their sensors. Using sensors that are connected by a wire link to a data logger and then via RF to the GPRS modem may be tolerable for an oncology outpatient but nearly impractical for a pediatric oncology outpatient. These problems can be overcome by advanced technologies in the development of intelligent sensors that also have built in RF transmission capabilities.

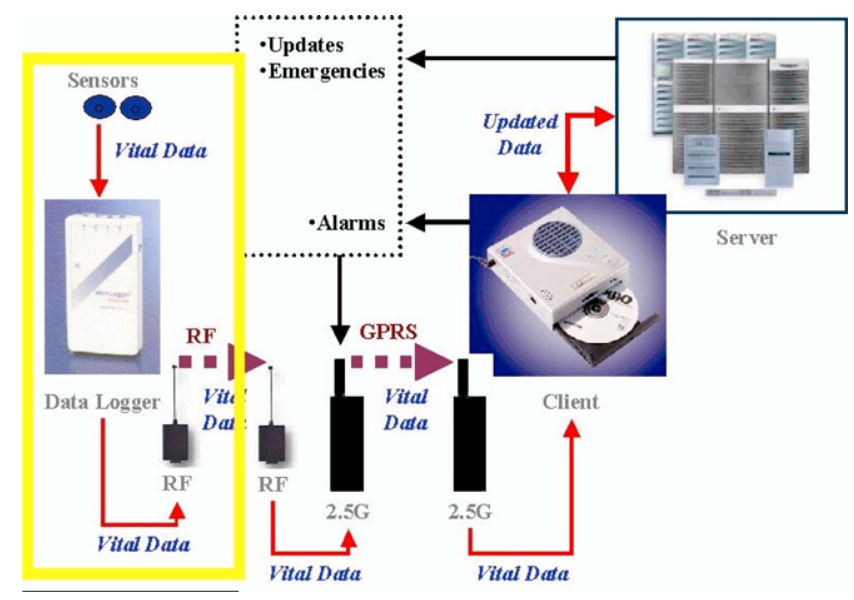

Fig.5. Step 5: Using wireless sensors

The five steps presented above have identified how off-the-shelf technologies can be used to support M-Safety and M-Healthcare services. However, to develop the envisaged $3 \mathrm{G}$ medical services the $3 \mathrm{G}$ communications networks will have to also be combined with advanced mobile handsets and PDA's with increased computation facilities.

\section{Step 6: Using advanced handsets}

By using medical data sensors with built-in RF transmission capabilities allows the patient to feel free of the monitoring equipment. As these wireless sensors are being developed supportive handsets will also be developed that will have built-in RF 
receivers to communicate with the sensors directly. The ideal user scenario would then be to also replace their home PC with an advanced handset that also had computing capabilities to calculate their personalized alarms.

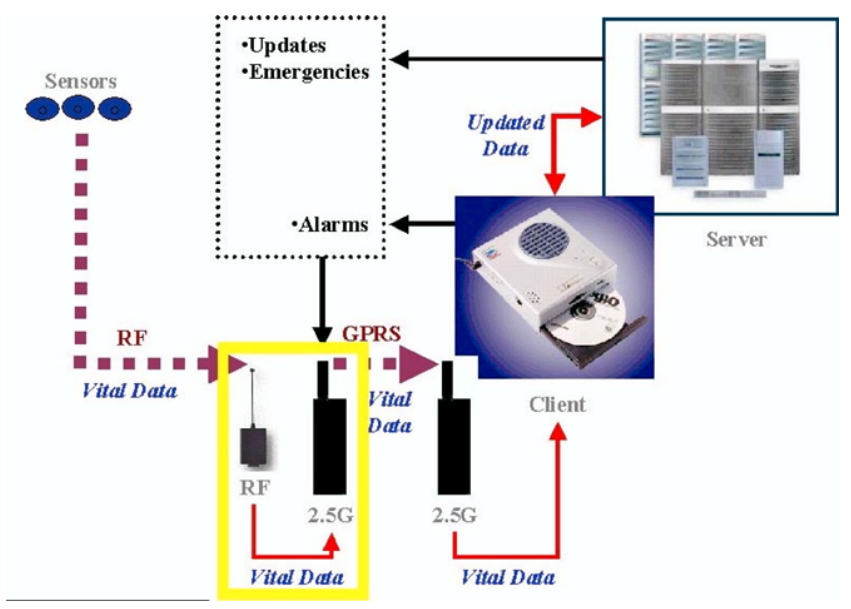

Fig. 6. Step 6: Using advanced handsets

\section{Step 7: Using advanced PDA's}

As the computing and networking capabilities of the PDA's are being developed effectively a single device can replace the patient's home PC and their mobile handset. The patients personalized alarms could also be calculated without any networking costs. The patient will then be in greater control of their healthcare whether at work, home or on the move. Additionally, their historic medical record could be kept on their PDA and accessed when required.

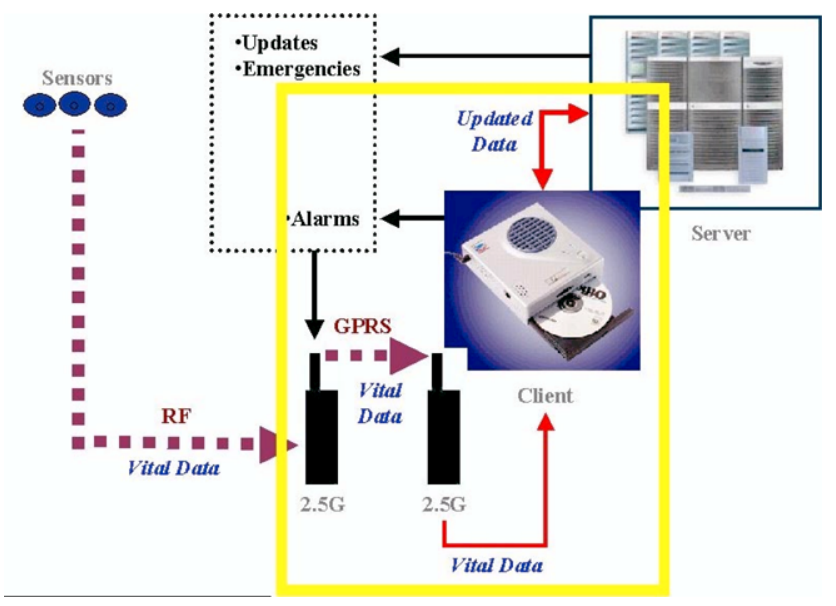

Fig.7. Step 7: Using advanced PDA's 


\section{Step 8: 3G Medical services}

Recording the patient's data over time on their PDA effectively means that the PDA will contain the Electronic Health Care Record (EHCR) of the patient. This could be taken into consideration when developing advanced medical services that will utilize the full $3 \mathrm{G}$ networks. With the predicted communication capabilities of UMTS networks it is envisaged that a number of advanced "tele-medical" services will be developed such as tele-consultation.

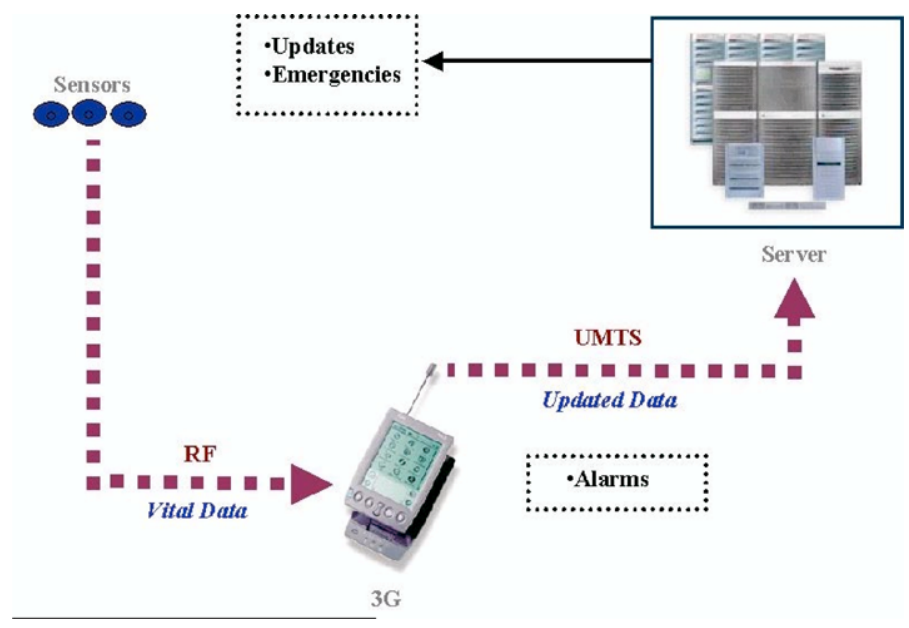

Fig. 8. Step 8: 3G Medical services

The eight steps above have defined a possible roadmap for the development of $3 \mathrm{G}$ Medical services. However, for such a range of services to become reality there needs to be an agreement on which standards, protocols and procedures etc that will be used. Additionally, when an agreement is reached there will also be a need to undertake some form of conformance testing.

\section{Conclusions}

For the successful development of $3 \mathrm{G}$ Medical services there needs to be an agreement on what types of categories of services will become available, how different complementary industries can work together to develop these services and how the developed services are certified. The rationale of this paper was to present the approach adopted within the E-care project. And to suggest that it could be used as a basis for deriving further $3 \mathrm{G}$ Medical services.

\section{Acknowledgements}

The author would like to thank the European Commission for supporting the E-CARE project (IST-2001-33261). 